\title{
COVID-19: An Emotional Analysis
}

\author{
Udit Khattar ${ }^{1}$ and Mukesh Kumar ${ }^{1}$
}

${ }^{1}$ Delhi Public School RK Puram, India

\section{$\underline{\text { ABSTRACT }}$}

In 2019, the Coronavirus (COVID-19) spread throughout the world. It was soon declared a pandemic by the World Health Organization (WHO). Following the declaration, many countries imposed lockdowns and various other restrictions on their citizens. Therefore, the aim of this study was to identify the differences in the emotional responses of the people, living in different countries, towards the lockdown. This was done by conducting an emotional analysis of the tweets of the citizens of Singapore, Italy, and USA after their respective governments' announcement of the lockdown by using an emotion-analyzing software. The results showed that there were significant differences between the three selected countries in terms of several emotional responses measured. The study revealed that the differences were influenced by sociocultural differences of the respective societies, the citizens' experience of the pandemic, and the efficacy of the government's response.

\section{Introduction}

On 31st December, 2019, the World Health Organization (WHO) China Office was informed of the occurrence of pneumonia from an unknown cause, which was detected in the city of Wuhan in the Hubei Province of China. Ten days later, WHO declared the cause of this illness to be Coronavirus Disease 2019, or COVID-19 ("Rolling Updates on COVID-19", 2020). Within the first week of March, 2020, the highly contagious disease had spread throughout the world, with the number of confirmed COVID-19 cases exceeding 100,000 worldwide ("Coronavirus disease 2019 (COVID-19), WHO Situation Report-47”, 2020). WHO characterized COVID-19 as a pandemic on 11 March, 2020 (Wetsman, 2020).

In an endeavour to curb the pandemic, governments in many countries declared lockdowns, requiring people to stay in their respective homes (Kaplan et al., 2020). Such a policy, which has led to the closure of stores (Thomas $\&$ Berk, 2020), the loss of livelihoods ("COVID-19: impact could cause equivalent of 195 million job losses", 2020), nationwide closure of schools that have affected over $60 \%$ of the world's student population ("Education: From Disruption to Recovery", 2020), and the decline in social interactions (Mehdi, 2020), has exerted a significant impact on people's lives. The spread of the pandemic has also led to an increase in economic inequality, as the people belonging to the lower economic strata are more likely to catch the disease due to their living and work conditions (Fisher \& Bubola, 2020). The United Nations has also reported a global rise in the crimes against women, linked to the lockdowns imposed by governments from around the world ("UN chief calls for domestic violence 'ceasefire' amid 'horrifying global surge'”, 2020). Thus, the prolonged lockdowns all over the world have taken a significant emotional toll on the people.

The aim of this study was to conduct an in-depth comparison of the specific emotional responses of residents living in three vastly different countries that had reached the community transmission stage of COVID-19, as revealed through the analysis of their tweets, by using an emotion-analysing software.

Twitter is an online microblogging and social networking service where users post and interact with messages up to 280 characters long. The messages are known as "tweets". Since its launch in 2006, Twitter has been used for a 
wide variety of uses: conversations, information sharing, and news commentary, among others. An important characteristic of the tweets is their relevance. Unlike blogs, they are so short that they tend to capture snapshots of specific moments in time (Bollen et al., 2009). Socio-linguistic researchers have indicated that Twitter has become a primary means for people to converse with other individuals, groups, and the world in general (Boyd et al., 2010). In fact, approximately 330 million active monthly Twitter users post 500 million tweets a day. As tweets often convey relevant information about their authors' mood and emotions (Bollen et al., 2009), they were used as a representation of the prevalent emotions of citizens during COVID-19.

Moreover, through the Advanced Search tool of Twitter, users can search tweets using parameters like hashtags [a hash symbol (\#) followed by one or more words, dates and specific words] which can point out the main topic of the tweet (Mohammad, 2012). Therefore, to easily find tweets related to the pandemic and the lockdown, this study used the Advanced Search tool of Twitter.

This research study also involved the use of Emotion Detection and Recognition or Emotional Analysis - a comparatively new field of research (Yam, 2015). Often used interchangeably with sentiment analysis, it is important to point out that they are not exactly same. Emotional analysis works by using natural language processing (NLP) and machine training to pair AI training data with predefined emotions in order to take into account different variations of human mental subjectivities (Allouch, 2018). It conducts a deep examination of human emotions and sensitivities by analysing the degrees and intensities associated with the deviations of each emotion. Therefore, tools used for emotional analysis enables one to detect and recognise specific types of feelings expressed through text, such as the four basic human emotions: happiness, sadness, anger and fear (Jack et al., 2014).

\section{Methodology}

\section{Research Aim and Research Approach}

In this research study, the differences in the presence of the following emotions - happiness, sadness, anger, excitement, fear, and boredom - between the tweets of the residents in the countries of Singapore, Italy, and the U.S. were investigated. The relevant hypotheses are stated as follows:

- Null Hypothesis: There are no differences in the emotional responses (happiness, sadness, anger, fear, boredom and excitement) of residents living in Singapore, Italy, and the U.S. towards the lockdown situation of the COVID-19 crisis.

- Alternative Hypothesis: There are differences in the emotional responses of residents living in Singapore, Italy, and the U.S. towards the lockdown situation of the COVID-19 crisis.

In addition, the quantitative analysis of the data would be situated within the specific contexts of these different countries. They had been deliberately selected due to the vast differences between their cultures and the institutional responses towards the COVID-19 situation. Thus, a mixed method research approach that included a qualitative exploration of perceptions of the residents from the different countries was employed. The results of this study would provide a revealing representation of the differences between countries in terms of:

- How the residents respond to unexpected crisis situations;

- The distinctive sociocultural characteristics of the countries; and

- The response of the respective government authorities to the crisis. 


\section{Sampling and Data Collection}

The following selection criteria were adopted in selecting Singapore, Italy and U.S. for this research study:

- Reached the community transmission stage with the countries having similar proportions:-

O Singapore: 2532 cases(till 12/4) in a population of 5.639 million (0.0004)

I Italy: 41,035 cases(till 19/3) in a population of 60.36 million (0.0006)

$\circ$ USA: $333,593($ till $5 / 4)$ cases in a population of 328.2 million $(0.001)$

- Belong to different continents, which could offer unique insights into the residents' responses and institutional measures, which differed due to geographical location and the timing of the severity of the crisis for the respective countries.

Once these countries were selected, a minimum of 20 tweets from each country was chosen. These tweets were collected from the time period when each country had just announced the nationwide lockdown, thus offering a common trigger of emotional responses across all the countries for comparison. As such, the tweets from the following time periods for the three countries varied accordingly:

1. Singapore: $2 / 4 / 2020$ to $12 / 4 / 2020$

2. Italy: $9 / 3 / 2020$ to $19 / 3 / 2020$

3. USA: $26 / 3 / 2020$ to $5 / 4 / 2020$

These tweets were collected using the advanced search tool of Twitter. Tweets of that particular time period of each country were filtered using specific hashtags pertaining to COVID-19 (like \#COVID19, \#lockdown etc) and 20 tweets were picked up from each country.

\section{Data Analysis}

All the collected tweets were analysed using an emotion-analysing software called ParallelDots AI (ParallelDots, 2020). Emotion Analysis, a subset of natural language processing, enables the emotions of the people, expressed through texts, to be quantified. Within the context of this research study, ParallelDots AI's Emotion Detection API was used to detect and quantify the proportion of aforementioned feelings found in the tweets in response to the COVID-19 situation in the three countries. This software used Deep Learning-powered machine learning algorithms to progressively extract a higher-level understanding of the features of the tweets. These features were then used to classify each emotion attached to the tweet. Then all the individual tweet results were compiled together for comparison, further evaluation and analysis.

Descriptive statistics were then used to set out the differences between the mean ratings of the different emotions of the residents of the three countries. Furthermore, six ANOVAs (one per emotion) were run to test the statistical significance of these differences. Finally, qualitative data, based on the actual tweets of the citizens of the respective countries, were also analysed in tandem with the literature to situate these findings within the real-life contexts of the pandemics as they affected each country.

\section{Results and Discussion}

Descriptive statistics comparing the average levels of the different emotions present in the tweets from Singapore, USA, and Italy indicate that there are substantial differences between them, in terms of the six different emotions. As 
shown in Figure 1, the tweets from Singapore registered the highest levels of Happiness and Excitement, while the tweets from the USA and Italy showed the highest levels of Anger and Sadness, respectively.

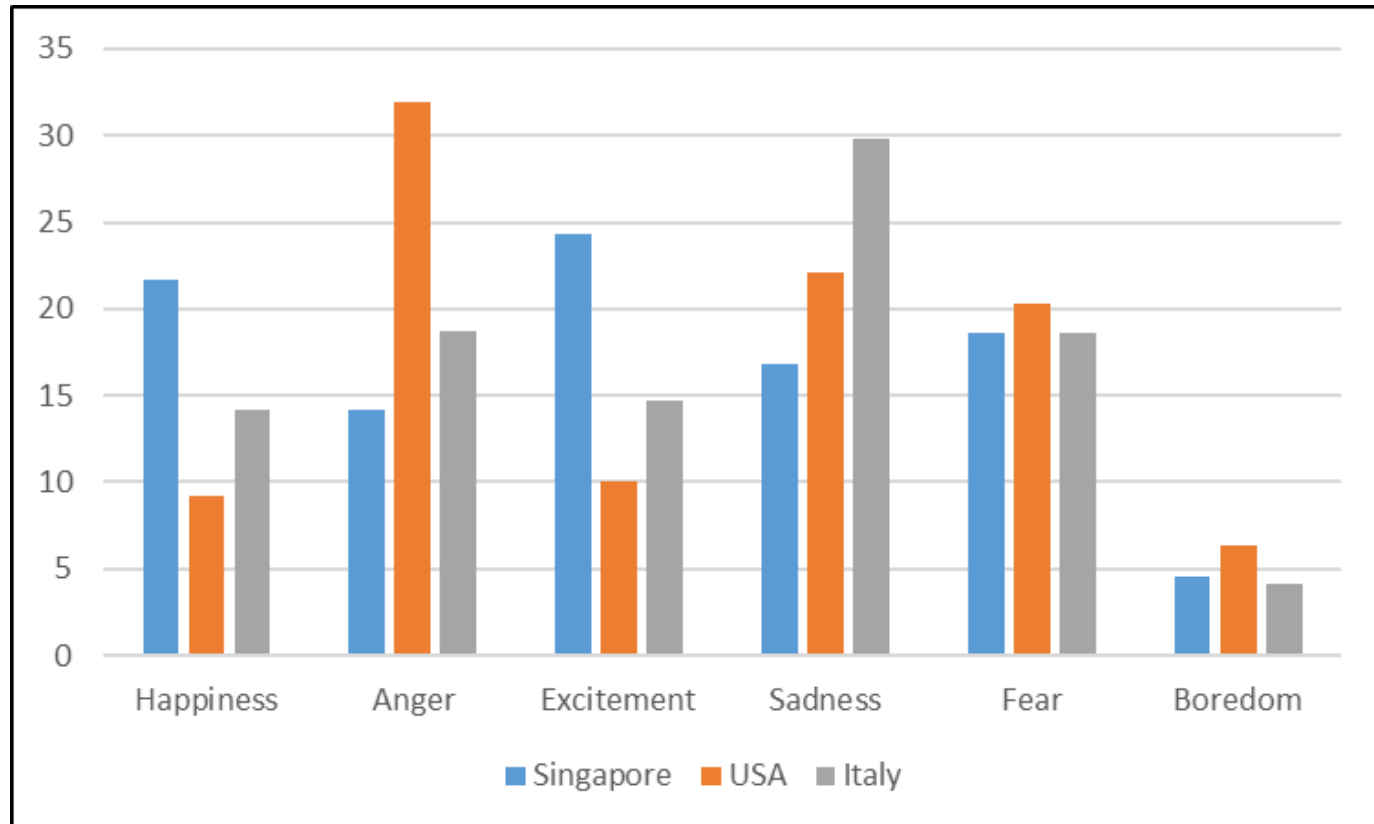

Figure 1. Differences in the Levels of Emotions between Singapore, USA, and Italy.

To determine whether the differences in the presence of these emotions are statistically significant, six one-way ANOVAs were run for each of the six emotions. The overall results show that the mean differences for the levels of emotions of fear and boredom between the three countries are statistically insignificant (see Appendix A). In the remaining sections, the differences in the levels of the statistically significant emotions, specifically happiness, anger, excitement and sadness, between the three countries, and their implications will be discussed in greater detail below.

\section{Happiness}

Descriptive statistics show that the tweets of Singapore $(M=21.63, S D=15.93)$ express the highest level of happiness among the three countries, followed by Italy $(M=14.21, S D=9.46)$ and USA $(M=9.25, S D=9.64$; see Table 1$)$.

Table 1. Descriptive Statistics for Happiness

\begin{tabular}{|c|c|c|c|c|c|c|}
\hline Countries & M & Median & SD & Range & Minimum & Maximum \\
\hline Singapore & 21.628 & 15.07 & 15.928 & 53.48 & 3.56 & 57.04 \\
\hline Italy & 14.209 & 13.095 & 9.457 & 29.14 & 3.03 & 32.17 \\
\hline USA & 9.247 & 5.305 & 9.636 & 42.2 & 3.04 & 45.24 \\
\hline
\end{tabular}

The one-way ANOVA for happiness shows that the differences between the average happiness levels of the three countries are statistically significant: $F(2,57)=5.34, p<.01$ (see Table 2 ).

Table 2. One-Way ANOVA Table for 'Happiness' 


\begin{tabular}{|c|c|c|c|c|c|c|}
\hline Source of Variation & SS & df & MS & F & $\boldsymbol{p}$-value & F crit \\
\hline Between Countries & 1553.01444 & 2 & 776.50722 & 5.34337838 & 0.00746582 & 3.158843 \\
\hline Within Countries & 8283.31972 & 57 & 145.321399 & & & \\
\hline & & & & & & \\
\hline Total & 9836.33416 & 59 & & & & \\
\hline
\end{tabular}

As one can see from the results, Singaporean tweeters are considerably happier than the Italian and American tweeters: the happiness levels of their tweets exceeded those of the latter two groups by 7.42 and 12.38, respectively. Five of the 20 tweets from Singapore were dominated by the emotion of happiness (see Appendix B). The high levels of happiness in these tweets can be seen in the sampling of three of these tweets with their accompanying emotional levels:

Stay home, stay safe. There's a rainbow after every storm. Rainbow after the rain in Bishan, Singapore this evening. (57.04)

Singapore claps to show our appreciation to Covid-19 front-line warriors! (48.05)

Kudos to @SingaporePolice for dispersion of the irresponsible people gathering during

\#CIRCUITBREAKER \#covid19Singapore. (53.04)

The sole USA tweet that registered the primary emotion of happiness scored 45.24 , lower than all the tweets from Singapore above:

A mailman has been dressing up in hilarious costumes each day to bring laughter to everyone quarantining on his route. \#COVID19USA.

Although there are four predominantly happy tweets from Italy, the highest level of happiness expressed is just 32.17 (see Appendix C).

Hard times in Italy... if you have family and friends here, especially if they are elders or not used to stay online, call them, send them messages, make them laugh.

And if you know any doctors or nurses here, thank them, thank them, thank them. \#Covid19 \#italylockdown (32.17)

\#italylockdown Santa Maria in Trastevere bell tower: at $8 \mathrm{pm}$, bells of all neighborhood churches rang for 10 min as sign of solidarity and prayer, for all those suffering from consequences of \#coronavirusitalia.

Studying these tweets exhibiting the predominant emotion of happiness offered a window into the universality of the human experience, which transcends societal and cultural barriers. Across all three countries, these predominantly happy tweets illuminate the beautiful aspects of human responses to adversity such as: seeing the positive in life (e.g., "rainbow" and "laughter"); showing gratitude for the front-line professionals (e.g., "appreciation" and "thank them"); and self-empowerment through activity, be it "clapping" or reaching out to the elderly, or "dressing up in hilarious costumes" to make others laugh.

At the same time, the analysis of the tweets also showcases the differences between the societies and the trajectory of the COVID-19 situation in each country. For instance, the happy tweet from Singapore regarding the police dispersal of people reflects the extent to which its citizens have been conditioned for decades to comply with 
the regulations of the government or risk punishment (Chor \& Campante, 2010). This could partially explain why Singaporean tweeters are substantially happier than their Italian and American counterparts. As a compliant populace used to following the government's lead, Singaporeans are more likely to be happy and content with the measures taken by the administration in response to the pandemic. To be fair, the small number of COVID-19 deaths in Singapore at the time of the announcement of the lockdown ("Singapore, praised for its COVID-19 response, goes into lockdown as cases rise", 2020) further helps to account for the Singaporean tweeters' relative level of happiness.

The tweets in Italy also appear to demonstrate two critical aspects relevant to this topic. First of all, the Italians' emphasis of social connections and the community can be seen in both the tweets (Irrera et al., 2020). While one calls for the need to continue to maintain social connections through online means, the other reminds the entire community of the importance of showing "solidarity". Furthermore, it is important to point out that both of these tweets contain sad references: "Hard times in Italy" and "suffering". This certainly attests to the high number of mortality cases in Italy (Harlan et al., 2020) and the devastating state of the Italian economy (Jones, 2020).

As for the solitary happy tweet from the USA, it certainly showcases the zany side of the American culture. Both the fact that a mailman is willing to take the initiative to dress up "in hilarious costumes" without feeling selfconscious and the people's acknowledgement could be construed to be a reflection of the expressive side of American culture.

\section{Anger}

The tweets of USA $(M=31.93, S D=19.09)$ show the highest level of anger among the three countries, followed by Italy $(M=18.69, S D=7.99)$ and Singapore $(M=14.13, S D=7.49$; see Table 3$)$.

Table 3. Descriptive Statistics for 'Anger'

\begin{tabular}{|c|c|c|c|c|c|c|}
\hline Countries & M & Median & SD & Range & Minimum & Maximum \\
\hline Singapore & 14.128 & 12.11 & 7.494 & 33.24 & 2.99 & 36.23 \\
\hline Italy & 18.688 & 18.735 & 7.998 & 36.15 & 2.29 & 38.44 \\
\hline USA & 31.933 & 28.11 & 19.09 & 72.39 & 5.34 & 77.73 \\
\hline
\end{tabular}

The one-way ANOVA for anger indicates that the differences between the average anger levels of the tweets from the three countries are statistically significant: $F(2,57)=10.59, p<.01$ (see Table 4 ).

Table 4. One-way ANOVA Table for 'Anger'

\begin{tabular}{|c|c|c|c|c|c|c|}
\hline Source of Variation & SS & df & MS & F & $\boldsymbol{p}$-value & F crit \\
\hline Between Countries & 3421.611 & 2 & 1710.8055 & 10.5916436 & 0.00012266 & 3.158843 \\
\hline Within Countries & 9206.87266 & 57 & 161.524082 & & & \\
\hline & & & & & & \\
\hline Total & 12628.4837 & 59 & & & & \\
\hline
\end{tabular}

The results show that the American tweets register far higher levels of anger than those from the Italian and Singaporean tweeters, exceeding the latter two groups by 13.25 and 17.81, respectively. As many as 11 tweets from the USA displayed extremely high levels of the predominant emotion of anger (see Appendix D):

Make your freaking wills and medical directives, folks. People are dying who aren't supposed to. \#COVID19US (77.73) 
The logic of the \#DonaldTrump government is very simple. If I don't have a mask, you're not allowed to wear it. If I don't use \#Huawei \#5G technology, you won't be allowed to use it. \#coronavirus \#COVID19 \#Covid19usa (66.45)

Jared Kushner is an insult to those actively engaged in managing the pandemic and caring for the sick. One word comes to mind about his role in this: indecent. \#COVID19 \#USA" (52.37)

In stark contrast, both Singapore and Italy had only one angry tweet each:

What's with people and the obsession with a lockdown? Please, do you all even know the implications of a lockdown? (36.23)

JUST IN: The Vicariate of Rome has ordered that all Churches in the diocese be closed until April 3, preventing Catholics even from praying before the Most Blessed Sacrament. \#italylockdown \#COVID2019 (34.59)

It is evident that the American tweeters were furious with the U.S. government leaders for the latter's delayed reaction, the lack of adequate medical resources (masks and PPEs) available and facilities, as well as the massive loss of lives. With regards to the solitary angry tweet from the one angry Italian, he/she reflects the devoutness of the Italian community that practises Catholicism. For them, not being able to go to the Church during Easter was very devastating.

\section{Excitement}

The tweets of Singapore $(M=24.35, S D=15.3)$ display the highest level of excitement among the three countries, followed by Italy $(M=14.66, S D=9.25)$ and USA $(M=10.09, S D=8.21$; (see Table 5$)$.

Table 5. Descriptive Statistics for 'Excitement'

\begin{tabular}{|c|c|c|c|c|c|c|}
\hline Countries & M & Median & SD & Range & Minimum & Maximum \\
\hline Singapore & 24.345 & 21.89 & 15.303 & 59.78 & 4.96 & 64.74 \\
\hline Italy & 14.659 & 9.935 & 9.25 & 27.31 & 2.32 & 29.63 \\
\hline USA & 10.087 & 7.245 & 8.21 & 37.92 & 2.6 & 40.52 \\
\hline
\end{tabular}

The one-way ANOVA for excitement shows that the differences between the average excitement levels of the three countries are statistically significant: $F(2,57)=8.22$,

$p<.01$ (see Table 6).

Table 6. One-Way ANOVA for 'Excitement'

\begin{tabular}{|c|c|c|c|c|c|c|}
\hline Source of Variation & SS & df & MS & F & p-value & F crit \\
\hline Between Countries & 2120.08229 & 2 & 1060.04115 & 8.21456946 & 0.00073313 & 3.158843 \\
\hline Within Countries & 7355.5097 & 57 & 129.04403 & & & \\
\hline
\end{tabular}




\begin{tabular}{|l|l|l|l|l|l|l|} 
& & & & & \\
\hline Total & 9475.59199 & 59 & & & & \\
\hline
\end{tabular}

Based on the results, the tweets from Singapore indicate far higher levels of excitement than those from Italy and the USA, exceeding the latter two groups by 9.69 and 14.26, respectively. There were six tweets from Singapore with the primary emotion of excitement (see Appendix B):

Winston Churchill - Success is not final, failure is not fatal; it is the courage to continue that counts. \#keepfighting \#covid19singapore (64.74)

Day 1 of \#CircuitBreaker. Keep healthy, maintain good hygiene and stay at home! The health of all depends on each one of us. (45.33)

The covid19 outbreak could slow down foreign investments, but Singapore's fundamentals remain strong and the reasons why global firms will want to invest in the country are still intact. (37.36)

While Italy had four tweets that show excitement, the highest level only reached 29.63 (see Appendix C):

We have no Wi-Fi \& bad signal, but we're making it work lo-fi style in the \#italylockdown — bringing back old school kids games, talking more (gasp!) and doing a lot of singing and dancing with the kiddos. (29.63)

The flash mobs in Italy today who played music from windows and balconies in the middle of a lockdown are a beautiful reminder that even in times of social isolation, we are social beings!!\#Covid19 \#CoronavirusPandemic \#italylockdown" (27.39)

\#italylockdown Day9 another behavioral change is the new choreography of the sidewalk: to avoid that rare someone walking toward you, very slowly gyrate as you move to cross the street to the other sidewalk - a kind of Tai Chi social distancing in the time of \#coronavirus?" (26.13)

In stark contrast, the USA had only one tweet showing excitement:

"Do not make decisions based on fear. Keep calm and keep carrying on during these difficult times. \#Wereallinthistogether \#FridayThoughts \#FridayMotivation \#COVID19Pandemic \#Covid19usa \#COVIDfrontlines" (40.52)

The Singaporean tweets suggest that the people have an overall positive outlook towards the lockdown. The Singaporeans seem to be optimistic and motivated about overcoming the crisis and doing their part to contribute to its resolution by maintaining proper hygiene and social distancing practices. One can thus see that the Singapore government's timely intervention with the COVID-19 pandemic and the economic strength of the Singapore government have given people tremendous confidence in riding through this situation. The government imposed a lockdown as soon as it saw the rise in the number of cases ("Singapore announces one-month lockdown", 2020) and it also announced that it would give additional support to some of the citizens ("9 in 10 Singaporeans will receive $\$ \$ 600$ pay out on Apr 14", 2020).

In comparison, the Italian tweets show a degree of resilience in striving to make the best of a bad situation such as the "no Wi-Fi \& bad signal". All three of them refer to music — singing and dancing — as a playful, defiant show of resistance to a disempowering situation. They definitely capture the Italians' playfulness and their love of connection with one another. 
What is interesting about the rating of the solitary American tweet with the predominant emotion of excitement was the message to tell people to "keep calm" — the antithesis of excitement. The reality is that the message's call for calmness actually reflects its underlying agitation characterized by "fear... during these difficult times".

\section{Sadness}

The tweets of Italy $(M=29.77, S D=16.15)$ show the highest level of sadness among the three countries, followed by those from USA $(M=22.06, S D=10.77)$ and Singapore $(M=16.76, S D=11.49$; see Table 7$)$.

Table 7. Descriptive Statistics of 'Sadness' in the 3 Countries

\begin{tabular}{|c|c|c|c|c|c|c|}
\hline Countries & M & Median & SD & Range & Minimum & Maximum \\
\hline Singapore & 16.76 & 17.085 & 11.492 & 36.2 & 1.21 & 37.41 \\
\hline Italy & 29.77 & 28.78 & 16.151 & 62.39 & 9.13 & 71.52 \\
\hline USA & 22.06 & 23.235 & 10.767 & 44.38 & 4.34 & 48.72 \\
\hline
\end{tabular}

The one-way ANOVA for Sadness shows that the mean differences of the average sadness levels between countries are statistically significant: $F(2,57)=5.04, \mathrm{p}<.01$ (see Table 8$)$.

Table 8. ANOVA Table of 'Sadness'

\begin{tabular}{|c|c|c|c|c|c|c|}
\hline Source of Variation & SS & df & MS & F & $p$-value & F crit \\
\hline Between Countries & 1710.13413 & 2 & 855.067065 & 5.04113282 & 0.00964081 & 3.158843 \\
\hline Within Countries & 9668.22824 & 57 & 169.618039 & & & \\
\hline Total & & & & & & \\
\hline
\end{tabular}

According to the results, the tweets from Italy are considerably sadder than the tweets from the USA and Singapore, exceeding the latter two groups by 7.7 and 13.01, respectively. Nine tweets from Italy display the main emotion of sadness (see Appendix C):

Rest in Peace, Italy!!! \#COVID \#CoronaAlert \#ChineseVirus \#CoronaOutbreak \#CoronavirusOutbreak \#Coronaitaly \#italylockdown" (71.52)

\#italylockdown waiting in line at Rome supermarket, only 3-4 allowed in at time. Ran out of batteries, tried three tobacconists before I found 2 packets. Took a hunk out of morning. Welcome, fellow Europeans to life in the anti/corona quarantine! (51.26)

Unbelievable scenes in Flag of Italy \#Italy as shoppers queue up the road to buy groceries as only a handful of people allowed in at a time. \#italylockdown \#italystaystrong (45.95)

The United States, on the other hand, had only 4 sad tweets, with the highest level of sadness being 48.72 (see Appendix D): 
USA cases are more than double those of Italy. Number of deaths is on track to catch up too. \#COVID19US (48.72)

On Thursday night as the confirmed \#coronavirus cases in \#NewYorkCity reached 51,809 and death toll 1,562, Doctor Krishan Kumar said that the hospitals were not prepared for the magnitude of the \#pandemic. \#COVID19USA (35.68)

Staggering. This is unprecedented (obviously), but will have dire consequences on the economy for years. \#COVID19US (25.67)

Although Singapore had 5 sad tweets, the highest level of sadness was only 37.41 (see Appendix B):

Ah this is the first time I see the trains are empty. \#circuitbreaker (37.41)

Singapore reports 142 new coronavirus cases. A total of 1,623 cases and 6 deaths so far. This is the highest number of cases per day Singapore has reported since the beginning of the outbreak. (29.96)

Singapore has been a leading light in COVID-19 control, but now appears to be entering a new phase, with half of the new cases untraceable. Reinforces that you can't take things for granted when fighting Covid19. (26.05)

There is no question that the tweets with the primary emotion of Sadness are inextricably interwoven with the development of the COVID-19 situation in the respective countries. For the Italian, the impact of the pandemic had been catastrophic. As the first country to be hit hard by COVID-19 in Europe, it suffered a high death toll near the start of the pandemic and the government's failure to respond in a timely fashion led to extreme suffering from the medical to the financial assistance rendered. Many Italians struggled to cope with daily living (Giuffrida, 2020).

The American tweets were also not far behind in their level of sadness. They were centred upon the rapidly rising number of cases, inadequate medical resources and the imminent plunge into economic crisis (Cowen, 2020).

In contrast, the sad tweets from Singapore simply comprise objective observations of the turn of events for the worse. However, as the death toll remains low, the tweets reflect a certain composure.

\section{Conclusion}

This research study has identified significant differences in the emotional responses of the residents living in Singapore, Italy and the U.S. towards the lockdown situation of the COVID-19 pandemic. After running the emotional analysis and the one-way ANOVA tests on the six different emotions: happiness, anger, excitement and sadness were identified as statistically significant. Overall, Singapore exhibited the highest level of happiness and excitement, whereas the U.S. and Italy exhibited the highest level of anger and sadness, respectively.

In general, Singapore's happy and excited response can be attributed to the timely response of the government and the support of the people. On the whole, Singapore's citizens respected the restrictions imposed on them and tended to follow the government orders. Due to the economic strength of Singapore and the government's swift intervention, the Singaporeans possessed an overall positive outlook towards the situation. However, during the latter part of the lockdown, as the number of cases began to accelerate due to the neglect the migrant workers in Singapore (Yea, 2020), the 'sad' tweets were generated.

Next, the Italians had an overall sad response to the situation. Italy was the first country in Europe to be hit by the pandemic and the circumstances looked very bleak for the Italians due to the high death toll near the start of 
the pandemic. Although the government took timely steps to contain the virus, it was unable to succeed in its task. This might have been due to the heightened pressure on the Italian healthcare system and Italy's ageing population (Khan, 2020). The pandemic also inflicted heavy damage on the Italian economy. The country's GDP suffered a huge blow ("Italy GDP Plunges $4.7 \%$ in Q1", 2020).

Finally, the United States displayed an overall emotion of anger. The American residents were furious with its government for its delayed reaction (Shear et al., 2020). The healthcare system of the USA was on the verge of collapse due to lack of medical resources and a huge number of cases ("COVID-19: US healthcare system, one of the best in the world, under deep stress", 2020). Some Americans even protested against the lockdown as they did not want to stay confined to their homes and they felt that the lockdown violated their fundamental rights (Maqbool, 2020). All of these factors could have contributed to the net angry response of the country.

Thus, the residents of different countries responded to the pandemic in different ways. The main cause of these differences include the socio-cultural characteristics, the toll exacted by the pandemic, and the efficacy of the government response. This research study shows the need for policymakers to be highly attuned to the particular sociocultural characteristics of their own populace, while being responsive to the universal characteristics of a crisis so that they can intervene in time.

\section{References}

Allouch, N. (2018, May 21). Sentiment and Emotional Analysis: The absolute difference. Emojics. https://www.emojics.com/blog/emotional-analysis-vs-sentiment-analysis/

Bollen, J., Pepe, A., \& Mao, H. (2009). Modeling public mood and emotion: Twitter sentiment and socio-economic phenomena. Proceedings of the 19th International Conference on World Wide Web, WWW, USA.

https://arxiv.org/abs/0911.1583

Boyd, D., Golder, S., \& Lotan, G. (2010). Tweet, tweet, retweet: Conversational aspects of retweeting on Twitter. Proceedings of the 43rd Hawaii International Conference on System Sciences (HICSS '10). IEEE Computer Society, USA, 1-10. https://doi.org/10.1109/HICSS.2010.412

Chor, D., \& Campante, F.R. (2010). Obedience, schooling, and political participation. Research Collection School of Economics. https://ink.library.smu.edu.sg/soe research/1256

COVID-19: 9 in 10 Singaporeans will receive $\$ \$ 600$ payout on Apr 14. (2020, April 12). ChannelNewsAsia. https://www.channelnewsasia.com/news/singapore/coronavirus-covid-19-solidarity-budget-600-cash-payout$\underline{12635268}$

COVID-19: Impact could cause equivalent of 195 million job losses, says ILO chief. (2020, April 8). UN News. https://news.un.org/en/story/2020/04/1061322

COVID-19: US healthcare system, one of the best in world, under deep stress. (2020, March 30). The Economic Times. https://economictimes.indiatimes.com/news/international/world-news/covid-19-us-healthcare-system-one-ofthe-best-in-world-under-deep-stress/articleshow/ 74887314.cms?from=mdr

Cowen, T. (2020, May 19). Covid-19 will expose the ghosts in the U.S. economy. Bloomberg-Opinion. https://www.bloomberg.com/opinion/articles/2020-05-19/covid-19-will-expose-the-many-ghosts-in-the-u-s-economy 
Fisher, M., \& Bubola, E. (2020, March 16). As coronavirus deepens inequality, inequality worsens its spread. The New York Times. https://www.nytimes.com/2020/03/15/world/ europe/coronavirus-inequality.html

Giuffrida, A. (2020, March 28). Reporting on Covid-19 in Italy: 'Life as we've known it has stopped'. The Guardian. https://www.theguardian.com/membership/2020/mar/28/coronavirus-reporting-italy-death-toll

Harlan, C., Pitrelli, S., \& Cavaliere, C. (2020, March 24). Italy's coronavirus deaths are staggering. They may be more preview than anomaly. The Washington Post. https:/www.washingtonpost.com/world/europe/why-is-coronavirus-so-bad-in-italy/2020/03/23/90d306d0-6c85-11ea-a156-0048b62cdb51 story.html

Irrera, A., Barbaglia, P., \& Caspani, M. (2020, March 14). Under lockdown, Italy's social and family life goes virtual. Reuters. https://in.reuters.com/article/us-health-coronavirus-italy-whatsapp/under-lockdown-italys-social-andfamily-life-goes-virtual-idINKBN2110VN

Italy GDP plunges 4.7\% in Q1 as coronavirus bites, steepest quarterly drop for at least 25 years. (2020, April 30). Reuters. https://www.reuters.com/article/italy-gdp-plunges-47-in-q1-as-corovaviru/italy-gdp-plunges-4-7-in-q1-ascorovavirus-bites-steepest-quarterly-drop-for-at-least-25-years-idUSR1N2A701Z

Jack, R. E., Garrod, O. G. B., \& Schyns, P. G. (2014, January 2014). Dynamic facial expressions of emotion transmit an evolving hierarchy of signals over time. Current Biology, 24(2), 187-192.

https://doi.org/10.1016/j.cub.2013.11.064

Jones, G. (2020, June 8). Italy statistics bureau forecasts GDP to fall 8.3\% in 2020 on coronavirus hit. Reuters. https://in.reuters.com/article/us-italy-economy-gdp-istat/italy-statistics-bureau-forecasts-gdp-to-fall-83-in-2020-oncoronavirus-hit-idINKBN23F0VB

Kaplan, J., Frias, L., \& Johnsen, M.M. (2020, April 17). A third of the global population is on coronavirus lockdown - here's our constantly updated list of countries and restrictions. Business Insider-India. https://www.businessinsider.in /international/ news/a-third-of-the-global-population-is-on-coronavirus-lockdown-x2014-hereapossour-constantly-updated-list-of-countries-and-restrictions/slidelist/75208623.cms

Khan, F. (2020, April 4). How Italy's ageing population, overburdened health system spiked its Covid-19 death rate. The Print. https://theprint.in/world/how-italys-ageing-population overburdened-health-system-spiked-its-covid-19death-rate/395369/

Maqbool, A. (2020, April 27). Coronavirus: The US resistance to a continued lockdown. BBC News. https://www.bbc.com/news/world-us-canada-52417610

Mehdi, S. (2020, April 11). Don't let the 'social recession' ruin your mental and physical health. The Hindu. https://www.thehindu.com/news/cities/Delhi/dont-let-the-social-recession-ruin-your-mental-and-physical-health/ar$\underline{\text { ticle31319862.ece }}$

Mohammad, S.M. (2012). Emotional tweets. Proceedings of the First Joint Conference on Lexical and Computational Semantics, Association for Computational Linguistics, USA, 246-255. https://dl.acm.org/doi/10.5555/2387636.2387676\#sec-ref

ParallelDots. (2020). Emotion Analysis. https://www.paralleldots.com/emotion-analysis 
Shear, M. D., Goodnough, A., Kaplan, S., Fink, S., Thomas, K., \& Weiland, N. (2020, March 28). The lost month: How a failure to test blinded the US to COVID-19. The New York Times. https://www.ny$\underline{\text { times.com/2020/03/28/us/testing-coronavirus-pandemic.html }}$

Singapore announces one-month lockdown. (2020, April 3). Livemint. https://www.livemint.com/news/world/singapore-announces-1-month-lockdown-amid-rising-corona-cases-11585905344421.html

Singapore, praised for its COVID-19 response, goes into lockdown as cases rise. (2020, April 3). Firstpost. https://www.firstpost.com/health/singapore-praised-for-its-covid-19-response-goes-into-lockdown-as-cases-rise$\underline{8225241 . h t m l}$

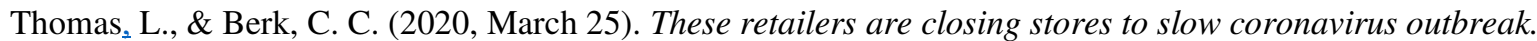
CNBC News. https://www.cnbc.com/2020/03/15/these-retailers-are-closing-stores-to-slow-coronavirus-outbreak.html

UN chief calls for domestic violence 'ceasefire' amid 'horrifying global surge'. (2020, April 6). UN News. https://news.un.org/en/story/2020/04/1061052

United Nations Educational, Scientific and Cultural Organization. Education: From disruption to recovery. Retrieved June 19, 2020, from https://en.unesco.org/ covid19/educationresponse

Wetsman, N. (2020, March 11). WHO declares the outbreak of the new coronavirus is a pandemic. The Verge. https://www.theverge.com/2020/3/11/21156325/coronavirus-pandemic-who-declares-covid-19-outbreak-global$\underline{\mathrm{h} 1 \mathrm{n} 1}$

World Health Organization. (2020, March 7). Coronavirus disease 2019 (COVID-19), (Situation Report-47). Retrieved from https://www.who.int/docs/default-source/coronaviruse/situation-reports/20200307-sitrep-47-covid19.pdf?sfvrsn=27c364a4 4

World Health Organization. Rolling updates on coronavirus disease (COVID-19). Retrieved June 11, 2020, from https:/www.who.int/emergencies/diseases/novel-coronavirus-2019/events-as-they-happen

Yam, C.Y. (2015, November 29). Emotion detection and recognition from text using Deep Learning. Microsoft CSE Developer Blogs. https://devblogs.microsoft.com/cse/2015/11/29/ emotion-detection-and-recognition-from-text-using-deep-learning/

Yea, S. (2020, 30 April). Why COVID-19 cases among Singapore's migrant workers are growing. The Wire. https://thewire.in/world/why-covid-19-cases-among-singapores-migrant-workers-are-growing 